\title{
Linking regional autonomy-embeddedness value orientation and innovation
}

Vladyslav Soloviov ${ }^{*}$ D

*Correspondence:

vladyslav.soloviov@ut.ee

School of Economics

and Business Administration,

University of Tartu, Narva mnt

18-4047, 51009 Tartu, Estonia

\begin{abstract}
Culture, as a key driver of innovative activity, has been largely analysed at the national and organisational levels by interdisciplinary studies. This article investigates the relationship between Schwartz's cultural dimensions and innovation, proxied by the number of patent applications to the European Patent Office, at the regional level. Using European Social Survey questionnaire, Eurostat and European Patent Office data and employing factor analysis and multilevel models, the link between culture and innovation is examined for regions of 26 European countries. The results of the analysis show that cultural differences are significantly related to differences in patenting even between regions of the same country. In particular, a higher autonomy-embeddedness score is significantly positively linked to patent applications at the regional level. The study highlights the usefulness of region-level cultural dimensions, providing evidence of more precise results obtained when these dimensions are used in the analysis.
\end{abstract}

Keywords: Regional culture, Patents, European Social Survey, Value orientations

\section{Introduction}

Variance in the innovative activities of different countries cannot be fully explained by economic factors, as variation in innovation exists even between countries with similar levels of economic development and entrepreneurial activity. One means of solving this puzzle involves combining economic data with cultural indicators to account for differences in the behavioural patterns of different groups of people in different countries and regions. Numerous studies confirm the link between culture and innovation (Kirkman et al., 2006, 2017). Such studies, however, mostly measure culture at the country level, which does not always reflect differences in the norms and beliefs of people living in different regions of a given country.

Several papers outline both the possibility and importance of using regional-level cultural indicators (Hofstede et al., 2010a; Kaasa et al., 2013, 2014). Such papers generally focus on Hofstede's theory, the first large-scale quantitative study that produced cultural data for future empirical studies. These data come in form of cultural dimensions, which are factors that represent distinct groups of cultural norms and patterns of behaviour. However, there has been severe criticism of Hofstede's cultural theory based

(c) The Author(s) 2022. Open Access This article is licensed under a Creative Commons Attribution 4.0 International License, which permits use, sharing, adaptation, distribution and reproduction in any medium or format, as long as you give appropriate credit to the original author(s) and the source, provide a link to the Creative Commons licence, and indicate if changes were made. The images or other third party material in this article are included in the article's Creative Commons licence, unless indicated otherwise in a credit line to the material. If material is not included in the article's Creative Commons licence and your intended use is not permitted by statutory regulation or exceeds the permitted use, you will need to obtain permission directly from the copyright holder. To view a copy of this licence, visit http:// creativecommons.org/licenses/by/4.0/. 
on the limited dataset employed (Fellows \& Liu, 2013), the obsoleteness of some of the resulting dimensions (Minkov \& Kaasa, 2020) and failures to replicate them (Minkov, 2018; Minkov \& Kaasa, 2020). This has prompted questions surrounding the suitability of using alternative cultural theories in the multidisciplinary analysis.

In this paper, I posit that cultural dimensions at a regional level can be quantified using cultural dimensions obtained following Schwartz's cultural theory, and that these, while retaining their country-level meaning, enhance the precision of empirical analysis. I create corresponding region-level cultural variables using the methodology previously applied to create country-level cultural scores (Schwartz, 2003) and cultural data collected over the past twenty years by the European Social Survey (ESS). The results of the empirical analysis that follows establish a significant positive relationship between the autonomy-embeddedness cultural dimension and patent applications at a regional level. This enhances the precision of analysis when using regional scores of value orientations and goes beyond the more commonly analysed cultural theory developed by Hofstede. The results also provide additional evidence of the usefulness of the ESS as a comprehensive source of cultural data.

This paper is divided into several sections. First, I discuss the main relevant cultural theories. Next, I provide a short overview of studies on culture and innovation and outline the research gap of studies on culture and innovation that this paper aims to bridge. This is followed by a description of the methodology and data used in the paper. Finally, I provide an overview of the results and possible applications of the obtained conclusions.

\section{Societal culture at the national and regional levels}

Numerous definitions of culture exist, which reflects the multifaceted nature of the term. To resolve such problem, many empirical studies employ a practical approach, striving to outline the group nature of culture and list its manifestations. Such definitions, therefore, correspond to different cultural theories used in these studies. For instance, Hofstede defined culture as a collective programming of the mind that separates one social group from another (Hofstede, 1980, 2001). Schwartz's definition, which is adopted by this paper, is that the culture is "a rich complex of meanings, beliefs, practices, symbols, norms, and values prevalent among people in a society" (Schwartz, 2006, p. 138). Culture incorporates aspects of group identity including attitudes, beliefs, norms, roles, values, and intentions. These aspects represent the average preferences of a group, its beliefs and views on acceptable behaviour, identity and life goals (Triandis, 1989).

When analysing a country's institutional framework, culture is often labelled an informal institution, as there is a reasonable overlap between their definitions. Informal institutions are commonly known unwritten rules of socially accepted and desirable behaviour that are similarly informally enforced. This contrasts with formal institutions, such as country's constitution, laws, economic policies and political power. As an informal institution, culture is interrelated with country's legal and economic systems, but cannot be treated as their substitute when performing an empirical analysis (Alesina \& Giuliano, 2015).

Culture has existed for as long as humanity has, but a lack of large-scale quantitative research hindered empirical analysis in this area until 1980, with Hofstede being the first to uncover and quantify several common cultural features, or 'dimensions', at 
the national level (Hofstede, 1980). Hofstede initially defined four cultural dimensions: individualism, power distance, masculinity and uncertainty avoidance. Hofstede's theory has since been expanded to include two additional dimensions (Hofstede \& Bond, 1988; Hofstede et al., 2010a). Hofstede's general framework has served as a reference point for most other cultural theories that have followed (Inglehart \& Baker, 2005; Schwartz, 1994).

Cultural differences can be hypothesised to be different in various regions of the same country for historical reasons. Indeed, culture is a group-centred concept, but groups do not have to be delimited by national borders. Hofstede et al. (Hofstede, Garibaldi de Hilal, et al., 2010), for example, hypothesised that within-country cultural variation exists between regions based on the differences between ethnic and religious groups. As Heine (2020) noted, norms and values established in different regions can remain entrenched for centuries due to cultural persistence, despite a country's, or even the world's, cultural shifts. The persistence of cultural norms in a given region can be explained by the fact that it is sufficient for a norm or value to be "weak" at an individual level, i.e. superficially recognised, rather than actively acted upon for collective values to be strongly observed and easily mimicked by immigrants through a phenomenon known as a memory of places (Todd, 2019). In particular, Hofstede et al. (Hofstede, Garibaldi de Hilal, et al., 2010) noted that for highly individualistic countries, rural regions sometimes retain strong collectivist elements.

Europe has a long-standing history of migrations, of military conflicts shifting national borders, and of a number of countries exhibiting a strong internal Catholic-Protestant divide. It is, therefore, plausible to assume the existence of separate regional culture dimensions for regions of European countries. Such regions, of course, must sufficiently differ in terms of the national averages of ethnic, religious and social distribution. Even though no region can have perfectly uniform cultural manifestations, cultural measurements at the regional level can offer a more reasonable representation of the more prominent differences within a country.

Some researchers (Kirkman et al., 2017) argue for an increased use of cultural indicators based on existing cultural theories but created for a particular study. Combined with the already discussed within-country cultural differences, it is reasonable to try utilising more precise measurements of culture by constructing them at the regional level. To do so, I utilise Schwartz's value orientation theory in this paper.

Schwartz's value orientation theory (Schwartz, 1994, 2006) is one of the prominent cultural theories distinct from Hofstede's. Schwartz proposed seven cultural indicators, or value orientations, that can be separated into three dimensions such that in each dimension, one orientation is the polar opposite to the other(s). These value orientations and their respective dimensions include mastery versus harmony, egalitarianism versus hierarchy, and embeddedness versus intellectual and affective autonomy. Because of the conflicting nature of the indicators of each dimension, a group that places higher value on one of the orientations automatically values the opposite orientation less.

The definition of value orientations is as follows. Autonomy scores reflect the importance of pursuing individual desires, with intellectual autonomy reflecting self-direction and affective autonomy being closely tied to hedonism. Embeddedness (originally conservatism) represents the importance of upholding group values over individual values. 
Mastery represents values tied to behaviour that actively changes or alters the environment, self-assertiveness and competitiveness. In contrast, harmony represents values of peace, justice and opposing active changes in the environment. Finally, the hierarchy score represents values that promote hierarchical roles in society and unequal resource distribution, while egalitarianism values viewing other members of a society as equals and opposes inequalities in social, legal, and work environments (Schwartz, 1994).

This study measures Schwartz's value orientations at a regional level based on the ESS via confirmatory factor analysis and following Schwartz's (2003) methodological guidelines. At the same time, this work utilises new rounds of surveys to enhance the precision of the resulting dimensions and obtain cultural dimension scores for more European countries than are included in Schwartz's original dataset.

\section{Linking culture and innovation}

Culture was highly relevant in the economic field long before its empirical formalisation, with some notable theories dating to the early twentieth century (Weber, 1905/1958). Such studies set out to explain how differences in culture had led to significant variance in the economic development of different European countries. Decades later, Hofstede's breakthrough led to a rapid increase in the number of studies published in the following years, through which culture has been linked to a number of economic concepts on a national, organisational and individual level, including human resource and conflict management, group process behaviour, foreign direct investments, entrepreneurship, and innovation (Kirkman et al., 2006). Among these, culture has been established among the factors linked to innovation, innovative activity and the capacity to innovate.

For a significant period, societal culture was analysed almost exclusively at a national level. This trend could be explained by data availability, an easier subdivision of cultural groups based on state borders, and the fact that many classic cultural theories constructed their dimensions at the national level. A common trend of such papers is a tendency to take the concept of national culture as given, largely without considering the possible limitations of such an approach. However, if culture is to be understood as a complex system of path-dependent beliefs, norms and values, it predates both the concepts of the nation-state and its modern borders, which are used to produce measurements for most cultural theories. Moreover, modern nations are political entities that are not always created based on a unified language, ethnicity or religion and that never perfectly match the former. This raises the question of whether a single set of cultural dimensions' scores for a whole country has any meaning if such a country is not fairly homogeneous in its cultural manifestations (Myers \& Tan, 2002).

Several papers provide a possible solution to this problem by separately analysing the cultures of different regions within a country. Beugelsdijk et al. (2006) find significant evidence of within-country variance using NUTS1 regional subdivision. The authors also link such variance to differences in economic development, employment and religion. Some single-country studies (see Didero et al., 2008) show significant variance in regional culture and its relation to innovation for, among others, the United States (James, 2005), Germany (Proff, 2007) and Italy (Stemmermann, 1996). A common feature of these studies is the identification of one or more distinct features between these 
regions: different coexisting religious beliefs or ethnic groups, historic ties to neighbouring regions of other countries, local institutions, degree of urbanisation, etc.

At the same time, as single-country studies are not able to fully utilise cultural dimensions to compare within- and between-group variance, it is necessary to turn to studies that utilise cultural data for groups of countries. For Europe specifically, several of such papers exist (Kaasa et al., 2013, 2014). According to the results of these papers, some European countries (e.g., Finland and Sweden) are fairly homogeneous, while for others, significant within-country cultural variance can be found at the NUTS1 (e.g., Germany and Spain) or NUTS2 (e.g., Portugal and Slovenia) levels. It is, therefore, reasonable to assume that regional subdivision when examining culture allows for a higher degree of precision at least partially corresponding to the religious and ethnic heterogeneity of the population.

The hypotheses listed in this section are treated as alternative hypotheses where the null hypothesis is the absence of the stated link. This is done strictly to reflect the existing consensus on the hypothesised sign of the link between the cultural variable and innovative activity and has no effect on the empirical analysis itself where a null hypothesis is rejected if $p$-value is below a threshold of 0.05 .

To hypothesise a link between regional culture and innovation, it is reasonable to consider existing results at the national level first and the described mechanisms that relate culture to innovation while noting the similarities and challenging the assumptions that do not transfer to the regional level. It is not possible to conduct such a review without mentioning Shane's (Shane, 1992, 1993; Shane et al., 1995) contribution to this field. Shane's early studies provide evidence that cultural conditions and circumstances, more so than simply economic conditions and infrastructure, play a significant role in encouraging innovation in a country. In particular, Shane specifies that three of Hofstede's dimensions are significantly correlated with national rates of innovation: high levels of individualism are a prerequisite to the desire to innovate, low power distance limits barriers to innovative activity, and low uncertainty avoidance enables an acceptance of ambiguity and risk linked to innovative activity.

Shane and many following researchers (Bukowski \& Rudnicki, 2019; Efrat, 2014; Kaasa \& Vadi, 2010; Van Everdingen, Waarts, 2003) have analysed cultural links to innovation using Hofstede's dimensions, and the results of their work provide a reasonable starting point from which to describe broad cultural traits that facilitate innovative activity. Such general conclusions should, in theory, be applicable regardless of the cultural theory utilised, even more so given that a significant correlation exists between Schwartz's and Hofstede's cultural indicators of interest (Schwartz, 1994). In general, societies that attach less importance to hierarchical structures tend to innovate more effectively and more often (Kaasa \& Vadi, 2010; Van Everdingen, Waarts, 2003). In addition, societies that either promote individual performance or create a permissive environment allowing for flexibility in completing professional tasks, on average, have higher rates of innovation (Bukowski \& Rudnicki, 2019).

These results can be linked to Schwartz's theory of values. Schwartz's egalitarianismhierarchy value orientation can be hypothesised to be significantly positively linked to innovation, as egalitarian values prevent the creation of strong hierarchies. It should be noted here, however, that this link might not be as pronounced for European countries, 
which exhibit a relatively low degree of variance in egalitarianism-hierarchy value orientation. Additionally, echoing Hofstede's power distance dimension, some degree of hierarchical structure can be beneficial for innovative activity by formulating clear rules and allocating resources to prospective projects. This might result in an inverted U-shaped relationship between egalitarianism-hierarchy and innovative activity. Additionally, as suggested by Dickson et al. (2003), it is argued that a direct and participatory style of leadership is employed in countries on the egalitarian pole of the dimension. This contrasts with the directive leadership of hierarchical countries, where direct participation is rare. As both styles of leadership can result in more innovative activity for the reasons noted above, I make the following hypothesis:

H1 Egalitarianism-hierarchy is significantly non-linearly linked to patent applications at the regional level with an inverted U-shaped relationship where average values of the orientation correspond to the largest number of patent applications.

Of further interest are Schwartz's autonomy dimensions opposing conservatism or embeddedness. It can be assumed that a significant positive link exists between the autonomy dimensions and innovation. The argument, in this case, is that a greater personal focus on freedom and less focus on preserving the status quo and societal order lead to a desire to voice and implement new ideas and, as a result, a greater propensity to innovate in such societies. Evidence of this link for national cultures can be found in Taylor and Wilson (2012).

H2 Autonomy-embeddedness is significantly positively linked to patent applications at the regional level.

For the final value orientation, mastery-harmony presents a challenge in formulating a hypothesis. On the one hand, societies with high mastery scores encourage personal achievements, which partially falls in line with the second part of the description of highly innovative societies. On the other hand, societies that score highly on a harmony scale create a culture of acceptance with a similar effect on innovation. As there is no way to a priori assess which effect is more beneficial for innovative activity or whether a moderate value of these value orientations creates the best or worst of both, no significant link will be hypothesised. In reflecting on the link between Hofstede's and Schwartz's cultural dimensions, it follows that the mastery-harmony value orientation resembles the masculinity-femininity dimension, for which results vary with no conclusive argument for either of the effects (compare Bukowski \& Rudnicki, 2019; Kaasa \& Vadi, 2010; Shane, 1992, 1993).

\section{Data}

This paper uses the European Union (EU) geocode standard nomenclature for territorial units known as NUTS. The highest-order level of this standard, known as NUTS1, corresponds to major socioeconomic regions, with each European country containing from one (the whole country) to sixteen NUTS1 regions.

Data for the empirical analysis are obtained for 26 European countries based on the availability of cultural and economic data. Cultural data are obtained from the biennial dataset from the ESS for the years 2002-2018. The survey monitors changes in attitudes and values across Europe and incorporates a core set of socio-structural questions as well as several rotating supplementary modules. The main focus of this empirical 
research is the list of 21 questions that measure human values according to Schwartz's theory (see Appendix A for descriptive statistics for the cultural data).

The aggregation of approximately 336 thousand observations using the ESS post-stratification weights results in a dataset covering 81 regions at the NUTS1 level. The following countries are analysed: Austria, Belgium, Bulgaria, Croatia, Cyprus, the Czech Republic, Denmark, Estonia, Finland, Germany, Greece, Hungary, Italy, Ireland, Latvia, Lithuania, Luxembourg, the Netherlands, Norway, Poland, Portugal, Slovenia, Slovakia, Spain, Sweden and the United Kingdom (UK). The regional level includes all NUTS1 regions for the abovementioned countries except for Åland, Azores and Madeira, as no sufficient cultural data could be collected for the analysis of these regions.

For the dependent variable of the regression, a logarithmic value of the number of patent applications of applicants registered in a given region is used. Patenting, as one of the indicators for national innovation capacity (Furman et al., 2002), has been used in innovation studies, including interdisciplinary studies (Kaasa \& Vadi, 2010). As an alternative to this indicator, granted patents by the region of applicant's origin were considered. However, as patent application review time is considerably long, this would introduce an increased time lag of indeterminate length between the dependent variable and socioeconomic control variables. In addition, the relative differences between countries when compared by either patents applied for or patents granted are relatively constant. Finally, these data were not available at the regional level in sufficient quantity. Data availability also prevented from conducting comparative analysis by industry.

Of course, not all potentially patentable innovations are ultimately patented. However, even the earliest papers on patents provide evidence that many commercial inventions would not have been possible if it were not for the protection patents provided (Mansfield, 1986). Additionally, as it is difficult to properly approximate a country's innovative activity, patents have become one of the acceptable estimates of its innovative processes (Crosby, 2000). A shortcoming of this approach is that patents and patent applications represent an industry-based approach to innovative activity, which can, in some cases, underrepresent the public sector contribution to the level of innovative activity within a given country or region.

Several other options were considered as a proxy for innovation, including the regionalised European Innovation Scoreboard values and Community Innovation Survey. Unfortunately, data for the former are mostly available at the NUTS 2 level, for which there is a lack of a sufficient number of responses from the ESS. The latter sample was rejected because of the smaller pool of countries it provided, thus lacking variety for a cross-cultural study.

Country- and regional-level socioeconomic data for the regression analysis are obtained from the Eurostat dataset for 2002-2018. These data represent factors related to different sources of impact on national innovation capacity: the state, academia and industry. At the country level, research and development (R\&D) expenditures per capita are included. At the regional level, lagged log GDP per capita and the share of the population with tertiary education are used (see Appendix B for the descriptive statistics of the socioeconomic data).

A higher share of the population with tertiary education and a higher GDP per capita can be viewed as prerequisites to more innovative activity by virtue of representing 
access to qualified labour and a higher level of economic activity. Country-level predictors generally represent common innovation inputs, such as those that drive innovation directly or are involved in knowledge creation (Halkos \& Tzeremes, 2013).

Confirmatory factor analysis at the regional level is used based on Schwartz's questionnaire to quantify value orientations describing culture for each region. This approach allows for the construction of accurate cultural indicators for several reasons. As noted by Schwartz (2003), items of the questionnaire reflect society's beliefs, goals and standards, which serve as cultural manifestations. This is true for other cultural questionnaires as well; however, Schwartz's questions also reflect the relative importance of one value orientation compared to the others, allowing for the clearer separation of cultural regions.

To apply a factor analysis, I first select Schwartz's list of 21 questions that allows for quantifying the value orientations of respondents. All questions follow a six-point scale, with 1 representing "not like me at all" and 6 representing "very much like me". It is important to note that such data are valuable not as absolute measures but only relative to other responses given by the same individual. Therefore, to analyse relative differences and reduce response style bias, the ipsatised scores of all questions were calculated by deducting a mean of all 21 questions from each question's score (Schwartz, 2003, 2004).

The data were then aggregated by region with the use of post-stratification weights provided in the ESS dataset to control for sampling error, non-response bias and different selection probabilities. This approach provides the appropriate age, gender, education and region representation, the last of which allows for meaningful results when comparing regions with a varying number of respondents. To contrast the findings with the country-level cultural indicators, I also performed a separate country-level aggregation using the same methods. Finally, the questions were separated into three cultural dimensions, each representing two or three value orientations that are strongly negatively correlated. This separation was performed based on Schwartz's (1994) analysis. A confirmatory factor analysis was then separately performed on all three dimensions. The first dimension includes questions related to mastery and harmony value orientations (Table 1), the second includes questions regarding embeddedness and intellectual and affective autonomy (Table 2), and the third consists of questions related to egalitarianism and hierarchy (Table 3). All three tables report both country- and region-level factor loadings.

Table 1 Factor analysis for the mastery-harmony dimension

\begin{tabular}{lcc}
\hline Item & Regional level & Country level \\
\hline It is important to show one's abilities and be admired & 0.79 & 0.8 \\
It is important to be successful and have people recognise one's & 0.76 & 0.77 \\
achievements & & 0.8 \\
It is important to get respect from others & 0.85 & -0.72 \\
It is important to care for nature and the environment & -0.64 & 0.748 \\
Cronbach's alpha & 0.725 & $59.8 \%$ \\
Explained variance, \% & $57.8 \%$ & 0.681 \\
KMO & 0.701 & \\
\hline
\end{tabular}

Source: calculated from European Social Survey data 
Table 2 Factor analysis for the autonomy-embeddedness dimension

\begin{tabular}{lcc}
\hline Item & Regional level & Country level \\
\hline It is important to think of new ideas and be creative & 0.85 & 0.77 \\
It is important to live in secure and safe surroundings & -0.8 & -0.8 \\
It is important to try new and different things in life & 0.53 & 0.53 \\
It is important to do what one is told and follow rules & -0.65 & -0.3 \\
It is important to understand different people & 0.7 & 0.67 \\
It is important to seek adventures and have an exciting life & 0.18 & 0.37 \\
It is important to have a good time & 0.75 & 0.7 \\
It is important to make one's own decisions and be free & 0.6 & 0.74 \\
It is important for the government to be strong and ensure safety & -0.74 & -0.85 \\
It is important to behave properly & -0.54 & -0.57 \\
It is important to follow traditions and customs & -0.88 & -0.88 \\
It is important to seek fun and things that give one pleasure & 0.72 & 0.68 \\
Cronbach's alpha & 0.868 & 0.864 \\
Explained variance, \% & $47.2 \%$ & $45.9 \%$ \\
KMO & 0.707 & 0.699 \\
\hline
\end{tabular}

Source: calculated from European Social Survey data

Table 3 Factor analysis for the egalitarianism-hierarchy dimension

\begin{tabular}{lcc}
\hline Item & Regional level & Country level \\
\hline It is important to be rich and have money and expensive things & -0.95 & -0.93 \\
It is important that people are treated equally and have equal opportunities & 0.73 & 0.8 \\
It is important to help people and care for others' well-being & 0.83 & 0.93 \\
It is important to be humble and modest and not draw attention to oneself & 0.63 & 0.37 \\
It is important to be loyal to friends and devoted to people close & 0.81 & 0.8 \\
Cronbach's alpha & 0.874 & 805 \\
Explained variance, \% & $69.7 \%$ & $62.6 \%$ \\
KMO & 0.781 & 0.741 \\
\hline
\end{tabular}

Source: calculated from European Social Survey data

The signs of the factor loadings for all of the questions for factor 1 align with mastery for the positive values of the factor and harmony for the negative ones. Additionally, the signs of the factor loadings are consistent with Schwartz's (2006) country-level research. For this value orientation, a slightly higher degree of variance is explained by country scores.

Similarly, the signs of the factor loadings for factor 2 align with autonomy for the positive values and embeddedness for the negative ones. The signs are consistent with those predicted by Schwartz (2006) except for the question on the importance of having an exciting life, which has a factor loading close to zero. Here, regional scores of a value orientation account for a higher portion of the underlying variance.

Finally, the signs of the loadings for factor 3 align with egalitarianism-hierarchy for the positive values and hierarchy for the negative ones, and all of the signs are consistent with prior research. Here, a larger part of the variance is explained by the regional value orientation scores.

The post-estimation tests show greater suitability for data aggregated at the regional level for the factor analysis of all variables. The scatterplots of the obtained cultural 




Fig. 1 Scatterplot of autonomy-embeddedness and mastery-harmony scores

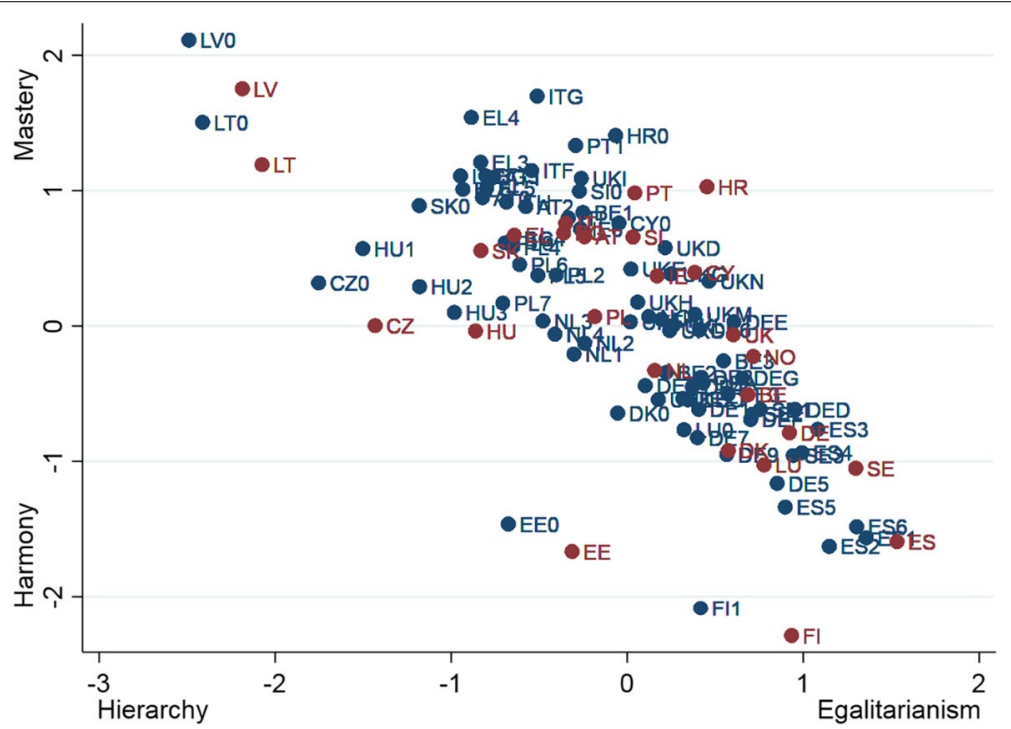

Fig. 2 Scatterplot of mastery-harmony and egalitarianism-hierarchy scores

variables at the regional level (blue) and country level (red) with mastery-harmony and autonomy-embeddedness axes (Fig. 1) and mastery-harmony egalitarianismhierarchy axes (Fig. 2) are shown below.

Because of the different sample sizes used, the absolute values for the cultural dimensions obtained from the factor analysis are not directly comparable to those obtained by Schwartz (2006). However, the relative positions of the country clusters remain largely similar. For instance, the significant difference in the mastery-harmony value orientation scores of West and East Germany, initially observed by Schwartz (2006), is reflected in the regional variation of this value orientation, with Berlin 
represented by the mean value of Germany's regional scores. The country scores are also reasonably close to the respective regional scores with no distinct outliers.

The resulting cultural factors at the regional level are sufficiently different for different regions of one country, yet the regional variance is usually smaller than the country variance for the whole sample, with each region presenting a score closer to its country average than to the other countries' scores. The within-country variance of the cultural dimensions for most countries is aligned such that each region has at least one dimension that exhibits variance across the regions. For instance, regions of Greece have a rather similar egalitarianism-hierarchy score but differ significantly in autonomyembeddedness and mastery-harmony, while Bulgaria's regions differ in their masteryharmony scores.

All cultural variables are normalised, as they were obtained by the means of factor analysis. As the normalisation of the data does not change correlations between the variables, and the exact coefficients of the non-cultural covariates are outside of the scope of the analysis, no additional data transformation has been performed. In addition, the interpretation of the analysis of the non-normalised data remains relatively straightforward.

\section{Methodology}

To investigate a link between culture and innovation, measured as the logarithm of patent applications, correlation and regression analysis is used. Spearman correlation is utilised for correlation analysis, as it is invariant to the logarithmic transformation of the patent applications variable and less sensitive to outliers across all variables. Pearson correlation was also employed with no significant changes in the strength or significance of the correlations, suggesting a significant monotonic and likely linear bivariate relationship between the cultural variables and dependent variable. For regression analysis, multilevel mixed-effects models with random intercepts were run using variables of culture at the regional level obtained from the factor analysis combined with the country- and region-level predictors. Multilevel modelling has been used to better explain the influence of different micro- and macro-level factors on innovation (Srholec, 2011). It allows to obtain better coefficient estimates despite high within-group correlation, which is reasonable to assume between cultures of different regions within a country. In addition, it allows to compare country- and region-level variation that is captured by the independent variables used in the regression. Finally, since culture is treated as a fixed in time for the purpose of the empirical analysis, a fixed-effects model cannot be employed.

For each multilevel model, regions are nested within countries with multiple observations used for each region. The observed innovation in different regions stems both from various framework conditions at the national level, such as economic, political and social conditions, and regional infrastructure and institutions, including culture. Hence, the independent variables with available data at the regional level are included at both the national and regional levels, providing an opportunity to better evaluate the link between culture at the regional level and patenting. There is also a need to separate the possible innovation link between the change in socioeconomic variables and the different static levels of such indicators. To do so, country means are created for such variables as a mean value for a variable over the years for each country. Variables with data 
available only at the country level are included as is. In the model below, years are represented by subscript $i$, regions are represented by subscript $j$, and countries are represented by subscript $k$. The regression model with country means is as follows:

$$
\begin{aligned}
\text { Pat }_{i j k}= & \beta_{0}+\beta_{1} \mathrm{MH}_{j k}+\beta_{2} \mathrm{AE}_{j k}+\beta_{3} \mathrm{EH}_{j k}+\beta_{4} \mathrm{GDPC}_{i j k}+\beta_{5} \mathrm{Tert}_{i j k} \\
& +\beta_{6} \mathrm{RDE}_{i k}+\beta_{7} \mathrm{GDPc}_{k}+\beta_{8} \mathrm{Tert}_{k}+u_{k}+v_{j k}+\varepsilon_{i j k},
\end{aligned}
$$

where $M H$ denotes mastery-harmony, AE denotes autonomy-embeddedness, EH denotes egalitarianism-hierarchy, $\mathrm{GDP}_{\mathrm{C}}$ denotes lagged GDP per capita, Tert denotes the share of the population with tertiary education, and $R D E$ denotes $R \& D$ expenditures per capita.

In the regression above, Pat $_{i j k}$ represents the number of patent applications submitted in the applicant's region of origin, $\left\{\mathrm{MH}_{i j k}, \mathrm{AE}_{i j k}, \mathrm{EH}_{i j k}, \mathrm{GDPC}_{i j k}, \mathrm{Tert}_{i j k}\right\}$ denote region-level socioeconomic and cultural effects, $\left\{\mathrm{RDE}_{i k}\right\}$ represents country-level effects and $\left\{\mathrm{GDP}_{k}, \mathrm{Tert}_{k}\right\}$ denote the country means. The regression was first run without the country means. The country means were then added but did not improve the regression fit. The third regression was employed to check for the inverted U-shaped relationship between egalitarianism-hierarchy and patenting with no country means added. Fourth and fifth regressions utilised country-level cultural variables $\left\{\mathrm{MH}_{j k}, \mathrm{AE}_{j k}, \mathrm{EH}_{j k}\right\}$ instead of regional variables. These were run, respectively, without and with the addition of country means. Year effects were utilised in all models.

\section{Results}

A correlation table of cultural factors and the number of patent applications is presented below (Table 4).

Patent applications are significantly positively related to the autonomy-embeddedness and egalitarianism-hierarchy dimensions and significantly negatively related to mastery-harmony. The correlations between value orientations and innovative activity are consistent with prior research for the latter two variables (Moonen, 2017; Taylor \& Wilson, 2012), with egalitarianism-hierarchy suggested to have a nonlinear relationship with innovative activity (Dickson et al., 2003). For the mastery-harmony

\begin{tabular}{|c|c|c|c|c|c|c|c|}
\hline & $\begin{array}{l}\text { Patent } \\
\text { applications }\end{array}$ & $\mathrm{MH}$ & $\mathrm{AE}$ & $\mathrm{EH}$ & MH (country) & $A E$ (country) & EH (country) \\
\hline Patent applications & 1 & & & & & & \\
\hline Mastery-harmony & $-0.36^{*}$ & 1 & & & & & \\
\hline $\begin{array}{l}\text { Autonomy-embed- } \\
\text { dedness }\end{array}$ & $0.63^{*}$ & $-0.63^{*}$ & 1 & & & & \\
\hline Egalitarianism-hierarchy & $0.34^{*}$ & $-0.86^{*}$ & $0.65^{*}$ & 1 & & & \\
\hline $\begin{array}{l}\text { Mastery-harmony } \\
\text { (country) }\end{array}$ & $-0.37^{*}$ & $0.96^{*}$ & $-0.65^{*}$ & $-0.86^{*}$ & 1 & & \\
\hline $\begin{array}{l}\text { Autonomy-embedded- } \\
\text { ness (country) }\end{array}$ & $0.58^{*}$ & $-0.66^{*}$ & $0.94^{*}$ & $0.67^{*}$ & $-0.67^{*}$ & 1 & \\
\hline $\begin{array}{l}\text { Egalitarianism-hierarchy } \\
\text { (country) }\end{array}$ & $0.43^{*}$ & $-0.88^{*}$ & $0.69^{*}$ & $0.96^{*}$ & $-0.9^{*}$ & $0.68^{*}$ & 1 \\
\hline
\end{tabular}

Table 4 Spearman correlation between cultural variables and patent applications

Significant at ${ }^{*} p=0.001$

Source: author's calculations 
dimension, the strength of the correlation is not as strong, which can be explained by the generally negative mastery-harmony scores found throughout Europe. The country-level cultural variables are more strongly correlated with each other and exhibit a similar correlation with patenting as the regional scores.

The results of the regression analysis are presented below (Table 5). The initial model is reported in regression (1), and a model with all country means is reported as a robustness check in regression (2). Both the LR test and Wald test show that the fit of the model does not improve after the addition of country means. Finally, to address the possibility of a nonlinear relationship between innovative activity and egalitarianism-hierarchy, a separate regression is run in (3) that includes an egalitarianism-hierarchy squared variable and otherwise follows the specification from (1). For regressions (4) and (5), specifications (1) and (3) are used, respectively, with cultural factors at the national level included instead of regional factors.

Table 5 Multilevel regressions on the regional-level patenting applications

\begin{tabular}{|c|c|c|c|c|c|}
\hline Factor & (1) & $(2)$ & (3) & (4) & (5) \\
\hline \multicolumn{6}{|c|}{ Cultural factors at the regional level } \\
\hline Mastery-harmony & $-0.373(0.252)$ & $-0.448(0.264)$ & $-0.475(0.299)$ & & \\
\hline $\begin{array}{l}\text { Autonomy- } \\
\text { embeddedness }\end{array}$ & $0.881^{* * *}(0.209)$ & $0.639^{* *}(0.257)$ & $0.874^{* * *}(0.182)$ & & \\
\hline $\begin{array}{l}\text { Egalitarianism- } \\
\text { hierarchy }\end{array}$ & $-0.237(0.24)$ & $-0.47(0.354)$ & $-0.62(0.383)$ & & \\
\hline $\begin{array}{l}\text { (Egalitarianism- } \\
\text { hierarchy) }^{2}\end{array}$ & & & $-0.31^{*}(0.158)$ & & \\
\hline \multicolumn{6}{|c|}{ Cultural factors at the country level } \\
\hline Mastery-harmony & & & & $-0.023(0.277)$ & $-0.078(0.301)$ \\
\hline $\begin{array}{l}\text { Autonomy- } \\
\text { embeddedness }\end{array}$ & & & & $0.769^{* * *}(0.242)$ & $0.776^{* * *}(0.223)$ \\
\hline $\begin{array}{l}\text { Egalitarianism- } \\
\text { hierarchy }\end{array}$ & & & & $0.283(0.237)$ & $0.209(0.268)$ \\
\hline $\begin{array}{l}\text { (Egalitarianism- } \\
\text { hierarchy) })^{2}\end{array}$ & & & & & $-0.119(0.111)$ \\
\hline \multicolumn{6}{|l|}{ Country-level predictors } \\
\hline R\&D spending & $<0.001(<0.001)$ & $<0.001(<0.001)$ & $<0.001(<0.001)$ & $<0.001(<0.001)$ & $<0.001(<0.001)$ \\
\hline \multicolumn{6}{|l|}{ Country means } \\
\hline Log GDP per capita & & $0.677(0.549)$ & & & \\
\hline Tertiary education & & $-0.106(0.254)$ & & & \\
\hline \multicolumn{6}{|l|}{ Region-level predictors } \\
\hline $\begin{array}{l}\text { Log GDP per capita } \\
(t-1)\end{array}$ & $0.492^{* *}(0.166)$ & $0.476^{* *}(0.165)$ & $0.489^{* *}(0.166)$ & $0.5^{* *}(0.164)$ & $0.499 * *(0.164)$ \\
\hline Tertiary education & $-0.018(0.041)$ & $-0.016(0.042)$ & $-0.018(0.041)$ & $-0.015(0.041)$ & $-0.015(0.041)$ \\
\hline Intercept & $1.477(1.477)$ & $-4.822(5.127)$ & $1.653(1.713)$ & $1.139(1.591)$ & $1.241(1.625)$ \\
\hline Observations & 1071 & 1071 & 1071 & 1071 & 1071 \\
\hline$\sigma_{c}^{2}$ & $0.418(0.328)$ & $0.35(0.294)$ & $0.44(0.321)$ & $0.299(0.265)$ & $0.28(0.264)$ \\
\hline$\sigma_{r}^{2}$ & $0.967(0.305)$ & $0.964(0.293)$ & $0.916(0.287)$ & $1.11(0.273)$ & $1.113(0.274)$ \\
\hline$\sigma_{\text {res }}^{2}$ & $0.069(0.016)$ & $0.069(0.016)$ & $0.069(0.016)$ & $0.069(0.016)$ & $0.069(0.016)$ \\
\hline AIC & 669.456 & 670.843 & 668.266 & 675.509 & 677.079 \\
\hline
\end{tabular}

Standard errors are shown in parentheses. Significance is measured at ${ }^{*} p=0.05,{ }^{* *} p=0.01$, and ${ }^{* * *} p=0.001$

Random slope variance: $\sigma_{c}^{2}$-country-level variance, $\sigma_{r}^{2}$-region-level variance, $\sigma^{2}$ res - residual variance

Source: author's calculations 
For all of the regressions listed above, the VIF score is less than 3, showing that the degree of multicollinearity in the models is reasonably low. All regressions were performed on a dataset of 26 countries and 81 regions with an average of 41.2 observations per country and 13.2 observations per region. Clustered standard errors at the country level and year effects were used for each regression.

Several additional robustness checks were performed on these results. First, the specifications above were rerun using only a single cultural variable at a time with no changes to the significance of the relationships. Next, to more directly represent the link between market competitiveness and innovation, an economic activity rate variable was added to the regression both as a region-level predictor and as a country mean. This did not improve the fit of the model however, and the variable itself was not significantly related to patent applications in any of the regressions. Finally, to check for an additional effect of high GDP per capita positively correlated with culture, an interaction variable of GDP per capita and autonomy was included in the analysis. This was also not found to be significant at $p=0.05$.

\section{Discussion}

Consistent with the earlier findings of Taylor and Wilson (2012), a significant positive relationship between autonomy-embeddedness and patenting was found at the regional level. Because regions with a higher score for affective autonomy represent social groups with more freedom to pursue personal goals and positive experiences, it is reasonable to assume that such groups will be more interested in new methods and activities and less punishing of failures, creating a greater demand for innovators. Cultures with a high score for intellectual autonomy, on the other hand, value creativity and curiosity, increasing the willingness of individuals to innovate. As it is unclear whether the supply or demand mechanism creates a stronger effect that results in higher innovative activity (Taylor \& Wilson, 2012), it is reasonable to assume that both components positively influence innovative activity to some degree. Autonomy is also closely related to Hofstede's individualism dimension, which has been proven to be significantly positively related to innovative activity (Bukovski \& Rudnicki, 2019; Shane, 1993). Egalitarianismhierarchy is significantly non-linearly linked to innovation at $p=0.05$ as hypothesised above. The fact that this link is not significant at $p=0.01$ can be attributed to the overall lesser regional variance in the scores of these variables, as within-country egalitarianism-hierarchy variance only accounts for $3 \%$ of the total variance. It could, however, also be caused by the correlation between cultural variables. Mastery-harmony is not significantly linked with innovation at $p=0.05$. This is consistent with the stated hypothesis; however, this result might also be caused by a significant positive correlation between mastery-harmony and autonomy-egalitarianism.

Cultural dimensions at the country level are similarly linked to innovation with the autonomy coefficient found to be statistically significant in all regressions. However, the regressions with cultural indicators at a regional level allow for a better fit of the model and reveal an additional nonlinear relation between egalitarianism and innovation. This 
result provides further evidence of a better prediction that cultural scores at a regional level offer accuracy compared to the country scores.

Lagged log GDP per capita is significantly positively related to patent applications at $p=0.001$. This is reasonable, as a higher GDP per capita might be associated with better conditions for innovative activity with higher levels of GDP growth being impacted by innovation in the long term. Neither R\&D spending nor share of population with tertiary education can be significantly linked with innovation at $p=0.05$. This could be interpreted as an absence of a link between such variables, however, as higher GDP per capita is significantly linked with an increase in both of these factors, it is possible to assume that GDP per capita is influencing innovation both directly and indirectly through the other two factors, which could be further explored in future empirical studies.

The above analysis shows the statistically significant link between autonomy-embeddedness and patent applications. It is worth noting that such measurements also have a sufficiently large regression coefficient for a link to be sufficiently impactful. For autonomy-embeddedness in particular, following from the results of the regressions, a one-point increase in the autonomy-embeddedness score is associated on average with an $87 \%$ increase in the patenting applications. Of course, such differences cannot be explained by cultural differences alone; however, as the prior analysis shows, they also cannot be explained solely by differences in economic development.

\section{Conclusions}

A summary of the hypothesised and discovered relations between cultural variables and innovative activity is presented in Table 6 .

The obtained results confirm a strong link between autonomy-embeddedness and patent applications at a regional level, providing evidence that the difference in cultural manifestations cannot be reduced to those defined by national borders. While some countries, such as Bulgaria and the Netherlands, exhibit little variance between regions, for some other countries, such as Austria, Germany, Spain and the UK, this difference can be significant. These indicators also offer an improved fit of the models relative to the country-level indicators and hint at the nonlinear relationship between egalitarianism-hierarchy and innovation. All of these results motivate the use of European regional cultural data, as they have better explanatory power than country-level cultural data.

When analysing culture using dimensions created at a regional level, it is important to remember that such measurements uncover previously ignored within-country

Table 6 Hypothesised and empirical link between culture and innovation

\begin{tabular}{llll}
\hline Variable & Hypothesised link & Empirical link (region) & Empirical link (country) \\
\hline Mastery-harmony & Not significant & Not significant & Not significant \\
Autonomy-embeddedness & Positive & Positive & Positive \\
Egalitarianism-hierarchy & Negative quadratic & Negative quadratic & Not significant \\
\hline
\end{tabular}

Source: based on the previous analysis 
variance. A significant portion of such variance stems from regional cultural manifestations: persistent and weakly dominating values and norms create environments with different attitudes towards personal encouragement and group conformity. Individuals from different cultures further blend the societal cultures of different regions and countries while quickly adapting to the manifestations of the host's culture (Todd, 2019). It is, therefore, not surprising that autonomy-embeddedness remains significantly linked to patent applications at the regional level, as this indicator exhibits the more withincountry variance in the analysed dataset.

More important than this is the fact that cultural indicators at the regional level by themselves have meaning-they represent small but robust differences between cultural manifestations within national borders. The regional cultural variance is small enough that no region is an outlier with regard to national averages, yet the differences are significant enough to warrant their use in empirical studies for a higher level of precision in results.

The results of this study have several practical implications. First, policymakers should be aware of how cultural changes enable or hinder innovation when establishing or changing existing policies. European countries might tailor their expectations of policies stimulating innovative activity and adjust their expectations accordingly. Secondly, businesses should be aware of differences in culture at the regional level, which might affect the speed and efficiency of creating or adopting innovations. The results of this paper can also be used as a background for case studies to investigate differences between regions of European countries and can be further explored by utilising aggregated firmlevel data on innovation and economic performance.

There are several limitations of the current empirical approach discussed in the paper. First, cultural values at the regional level were obtained using regional borders, yet it is possible that heterogeneity of culture within a country is based on another aspect, such as a common language or religion. In this regard, these measurements retain the shortcoming of the country-level cultural dimensions by also being border-bound. Secondly, the cultural dimension at the regional level are obtained by pooling data from different years. It is possible that culture of these regions might have changed over the observed period, though unlikely in a major way. This is largely a limitation of the initial survey data, as each region included in the analysis requires a sufficient number of observations to produce a robust measurement. Finally, it is possible that using another cultural theory as a starting point for creating cultural dimensions at a regional level would produce more internally consistent measurements.

The broader implication of this study is the significance of metrics of culture at the regional level for interdisciplinary empirical research. As the results of this study show, differences in culture at the regional level are significantly linked to the differences in innovative activity as represented by patent applications in the current paper. In addition, in line with Kaasa et al. (2014), regions of some of the analysed countries are culturally closer to the neighbouring regions of different countries than to other regions of their own country. This makes cultural differences between these regions less 
pronounced than those between the respective countries, leading to more accurate predictions when regional dimensions of culture are used. This also suggests that regional cultural indicators can be used in future papers analysing economic links by utilising spatial econometrics. As the results of this paper show, it is also possible to obtain such regional measurements using social surveys. The resulting measurements, of course, must conform to existing cultural theories for the empirical results to be meaningful.

In future research, it will be reasonable to test subdivisions other than the one used in this paper. Culture may also be differently related to innovation at the regional and country levels, which warrants separate research. A replication of the results of this study to a broader range of countries could provide stronger evidence for the use cultural variables at the regional level.

Appendix A

Descriptive statistics for the cultural data

See Table 7.

Table 7 Descriptive statistics of the ipsatised values of Schwartz's questionnaire

\begin{tabular}{|c|c|c|c|}
\hline Question & Answer ranges & Mean* & Std. dev.* \\
\hline It is important to show one's abilities and be admired & \multirow{21}{*}{$\begin{array}{l}1=\text { not like me at all, } \\
6=\text { very much like me }\end{array}$} & 0.176 & 0.035 \\
\hline $\begin{array}{l}\text { It is important to be successful and have people recognise one's } \\
\text { achievements }\end{array}$ & & -1.295 & 0.059 \\
\hline It is important to seek adventures and have an exciting life & & 0.665 & 0.031 \\
\hline It is important to care for nature and the environment & & -0.388 & 0.053 \\
\hline It is important to be rich and have money and expensive things & & 0.407 & 0.046 \\
\hline $\begin{array}{l}\text { It is important that people are treated equally and have equal } \\
\text { opportunities }\end{array}$ & & -0.195 & 0.023 \\
\hline It is important to help people and care for others' well-being & & -0.403 & 0.063 \\
\hline It is important to get respect from others & & 0.344 & 0.043 \\
\hline It is important to be loyal to friends and devoted to people close & & -0.008 & 0.054 \\
\hline It is important to think of new ideas and be creative & & -0.171 & 0.078 \\
\hline It is important to live in secure and safe surroundings & & 0.554 & 0.032 \\
\hline It is important to try new and different things in life & & 0.528 & 0.037 \\
\hline It is important to do what one is told and follow the rules & & -0.370 & 0.052 \\
\hline It is important to understand different people & & 0.397 & 0.043 \\
\hline $\begin{array}{l}\text { It is important to be humble and modest and not draw attention } \\
\text { to oneself }\end{array}$ & & -1.099 & 0.044 \\
\hline It is important to have a good time & & 0.091 & 0.035 \\
\hline It is important to make one's own decisions and be free & & -0.412 & 0.049 \\
\hline It is important that government is strong and ensures safety & & 0.805 & 0.043 \\
\hline It is important to behave properly & & 0.594 & 0.024 \\
\hline It is important to follow traditions and customs & & 0.021 & 0.038 \\
\hline It is important to seek fun and things that give one pleasure & & -0.242 & 0.064 \\
\hline
\end{tabular}

*Post-stratification weights are used. Population size N=308 799

Source: calculated from European Social Survey data 


\section{Appendix B}

\section{Descriptive statistics for the socioeconomic data}

\begin{tabular}{lccll}
\hline Variable & Mean & Std. dev & Min & Max \\
\hline Lagged logarithm of GDP per capita, $€$ & 10.1052 & 0.5486 & 8.4392 & 11.2587 \\
Gross domestic R\&D expenditure per capita, $€$ & 555.15 & 381.6021 & 10.3 & 1615 \\
Population with tertiary education, \% & 3.8636 & 1.2497 & 0 & 9.9374 \\
\hline
\end{tabular}

\section{Source: calculated from Eurostat data}

\section{Abbreviations}

ESS: European Social Survey; EPO: European Patent Office; NUTS: Nomenclature of territorial units for statistics; EU: European Union; GDP: Gross domestic product; R\&D: Research and development; UK: United Kingdom.

Acknowledgements

The author would like to express his gratitude to Anneli Kaasa and Tomasz Mickiewicz for their comments on the initial drafts of this paper.

\section{Authors' contributions}

VS, as the sole author, wrote the theoretical overview, performed empirical analysis and recorded the obtained results. All authors read and approved the final manuscript.

\section{Funding}

This article was supported by the Estonian Research Council under Grant PRG380.

\section{Availability of data and materials}

The datasets used and/or analysed during the current study are available from the corresponding author on reasonable request.

\section{Declarations}

\section{Competing interests}

The author declares no conflicts of interest.

Received: 1 March 2021 Accepted: 12 January 2022

Published online: 20 February 2022

\section{References}

Alesina, A., \& Giuliano, P. (2015). Culture and Institutions. Journal of Economic Literature, 53(4), 898-944.

Beugelsdijk, S., Van Schaik, T., \& Arts, W. (2006). Toward a unified Europe? Explaining regional differences in value patterns by economic development, cultural heritage and historical shocks. Regional Studies, 40(3), 317-327.

Bukowski, A., \& Rudnicki, S. (2019). Not only individualism: the effects of long-term orientation and other cultural variables on national innovation success. Cross-Cultural Research, 53(2), 119-162.

Crosby, M. (2000). Patents, innovation and growth. Economic Record, 76, 255-262.

Dickson, M. W., Den Hartog, D. N., \& Mitchelson, J. K. (2003). Research on leadership in a cross-cultural context: making progress, and raising new questions. The Leadership Quarterly, 14, 729-768.

Didero, M., Gareis, K., Marques, P., \& Ratzke, M. (2008). Differences in innovation culture across Europe. Transformative Use of ICT in EU Regions. Transform

Efrat, K. (2014). The direct and indirect impact of culture on innovation. Technovation, 34, 12-20.

Fellows, R., \& Liu, A. M. M. (2013). Use and misuse of the concept of culture. Construction Management and Economics, $31(5), 401-422$.

Furman, J., Porter, M., \& Stern, S. (2002). The determinants of national innovative capacity. Research Policy, 31 (6), 899-933.

Halkos, G. E., \& Tzeremes, N. G. (2013). Modelling the effect of national culture on countries' innovation performances: a conditional full frontier approach. International Review of Applied Economics, 27(5), 656-678.

Heine, S. J. (2020). Cultural psychology (4th ed.). W.W. Norton.

Hofstede, G. (1980). Culture's consequences: international differences in work-related values cross cultural research and methodology. SAGE.

Hofstede, G. (2001). Culture's consequences: comparing values, behaviors, institutions, and organizations across nations (2nd ed.). Sage.

Hofstede, G., \& Bond, M. (1988). The Confucius connection: from cultural roots to economic growth. Organizational Dynamics, 16, 4-21.

Hofstede, G., Garibaldi de Hilal, A. V., Malvezzi, S., Tanure, B., \&Vinken, H. (2010). Comparing regional cultures within a country: lessons from Brazil. Journal of Cross-Cultural Psychology, 41(3), 336-352. 
Hofstede, G., Hofstede, G. J., \& Minkov, M. (2010a). Cultures and organizations, software of the mind. Intercultural Cooperation and Its Importance for survival. McGraw-Hill

Hofstede, G., Hofstede, G. J., \& Minkov, M. (2010b). Cultures and organizations: software of the mind (3rd ed.). McGraw-Hill. Inglehart, R., \& Baker, W. E. (2005). Modernization, cultural change, and the persistence of traditional values. American Sociological Review, 65, 19-51.

James, A. (2005). Demystifying the role of culture in innovative regional economics. Regional Studies, 39(9), 197-1216.

Kaasa, A., \& Vadi, M. (2010). How does culture contribute to innovation? Evidence from European Countries. Economics of Innovation and New Technology, 19(7), 583-604.

Kaasa, A., Vadi, M., \& Varblane, U. (2013). European Social Survey as a source of new cultural dimensions estimates for regions. International Journal of Cross Cultural Management, 13(2), 137-157.

Kaasa, A., Vadi, M., \& Varblane, U. (2014). Regional cultural differences within European countries: evidence from multicountry surveys. Management International Review, 54(6), 825-852.

Kirkman, B., Lowe, K., \& Gibson, C. (2006). A quarter century of culture's consequences: a review of empirical research incorporating Hofstede's cultural values framework. Journal of International Business Studies, 37(3), 285-320.

Kirkman, B., Lowe, K., \& Gibson, C. (2017). A retrospective on culture's consequences: the 35-year journey. Journal of International Business Studies, 48(1), 12-29.

Mansfield, E. (1986). Patents and innovation: an empirical study. Management Science, 32(2), 173-181.

Mansury, M., \& Love, J. (2008). Innovation, productivity and growth in US business services: a firm-level analysis. Technovation, 28(1-2), 52-62.

Minkov, M. (2018). A revision of Hofstede's model of national culture: old evidence and new data from 56 countries. Cross Cultural \& Strategic Management, 25(2), 231-256.

Minkov, M., \& Kaasa, A. (2020). A test of Hofstede's model of culture following his own approach. Cross Cultural \& Strategic Management

Moonen, P. (2017). The impact of culture on the innovative strength of nations: a comprehensive review of the theories of Hofstede, Schwartz, Boisot and Cameron and Quinn. Journal of Organizational Change Management, 30(7), $1149-1183$.

Myers, M. D., \& Tan, F. B. (2002). Beyond models of national culture in information systems research. Journal of Global Information Management, 10(1), 24-32.

Proff, H. (2007). Kompetenzaufbau, Produktinnovationen und der Einfluss von kultureller Vielfalt. In G. Koch \& B. J. Warneken (Eds.), Region - Kultur-Innovation. Wege in die Wissensgesellschaft (pp. 169-183). Wiesbaden: VS Verlag für Sozialwissenschaften.

Rodríguez-Pose, A., \& Crescenzi, R. (2008). Research and development, spillovers, innovation systems, and the genesis of regional growth in Europe. Regional Studies, 42(1), 51-67.

Schwartz, S. (1994). Beyond individualism/collectivism: new cultural dimensions of values. In U. Kim, H. C. Triandis, C. Kagitcibasi, S. C. Choi, \& G. Yoon (Eds.), Individualism and collectivism: theory, method, and applications (pp. 85-119). Sage.

Schwartz, S. H. (2003). A proposal for measuring value orientations across nations. Chapter 7 in the Questionnaire Development Package of the European Social Survey. Website: www.Europeansocialsurvey.org.

Schwartz, S. H. (2004). Mapping and interpreting cultural differences around the world. In H. Vinken, J. Soeters, \& P. Ester (Eds.), Comparing cultures: dimensions of culture in a comparative perspective (pp. 43-73). Brill.

Schwartz, S. H. (2006). A theory of cultural value orientations: explication and applications. Comparative Sociology, 5, 137-182.

Shane, S. (1992). Why do some societies invent more than others? Journal of Business Venturing, 7(1), 29-46.

Shane, S. (1993). Cultural influences on national rates of innovation. Journal of Business Venturing, 8(1), 59-73.

Shane, S., Venkataraman, S., \& MacMillan, I. (1995). Cultural differences in innovation championing strategies. Journal of Management, 21(5), 931-952.

Srholec, M. (2011). A multilevel analysis of innovation in developing countries. Industrial and Corporate Change, 20(6), 1539-1569.

Stemmermann, K. (1996). Gibt es einen italienischen Wirtschaftsstil? In R. Klump (Ed.), Wirtschaftskultur, Wirtschaftsstil und Wirtschaftsordnung. Methoden und Ergebnisse der Wirtschaftskulturforschung (pp. 93-123). Marburg: Metropolis.

Taylor, M. Z., \& Wilson, S. (2012). Does culture still matter? The effects of individualism on national innovation rates. Journal of Business Venturing, 27, 234-247.

Todd, E. (2019). The memory of places. In E. Todd (Ed.), Lineages of modernity a history of humanity from the stone age to homo Americanus (pp. 298-309). Polity.

Triandis, H. C. (1989). The self and social behavior in differing cultural contexts. Psychological Review, 96(3), 506-520.

Van Everdingen, Y. M., \& Waarts, E. (2003). The effect of national culture on the adoption of innovations. Marketing Letters, 14(3), 217-232.

Weber, M. (1905). The Protestant ethic and the spirit of capitalism. Scribner.

\section{Publisher's Note}

Springer Nature remains neutral with regard to jurisdictional claims in published maps and institutional affiliations. 